\section{OPEN ACCESS}

Edited by:

Lang Wang,

Zhejiang University, China

Reviewed by:

James M. Tepper,

The State University of New Jersey,

United States

Shuijin $\mathrm{He}$,

ShanghaiTech University, China

${ }^{*}$ Correspondence:

Minmin Luo

luominmin@nibs.ac.cn

tThese authors have contributed equally to this work

Specialty section:

This article was submitted to Cellular Neurophysiology,

a section of the journal

Frontiers in Cellular Neuroscience

Received: 01 March 2021

Accepted: 29 April 2021

Published: 08 June 2021

Citation:

Ren Y, Liu Y and Luo M (2021) Gap Junctions Between Striatal D1

Neurons and Cholinergic

Interneurons.

Front. Cell. Neurosci. 15:674399.

doi: 10.3389/fncel.2021.674399

\title{
Gap Junctions Between Striatal D1 Neurons and Cholinergic Interneurons
}

\author{
Yuqi Ren ${ }^{1,2,3 t}$, Yang Liu' ${ }^{4,5 t}$ and Minmin Luo $3,6,7 *$ \\ ${ }^{1}$ School of Life Sciences, Peking University, Beijing, China, ${ }^{2}$ Peking University-Tsinghua University-NIBS Joint Graduate \\ Program, Beijing, China, ${ }^{3}$ National Institute of Biological Sciences, Beijing, China, ${ }^{4}$ School of Life Sciences, Tsinghua \\ University, Beijing, China, ${ }^{5}$ Tsinghua-Peking Joint Center for Life Sciences, Tsinghua University, Beijing, China, ${ }^{6}$ Chinese \\ Institute for Brain Research, Beijing, China, ${ }^{7}$ Tsinghua Institute of Multidisciplinary Biomedical Research, Beijing, China
}

The striatum participates in numerous important behaviors. Its principal projection neurons use GABA and peptides as neurotransmitters and interact extensively with interneurons, including cholinergic interneurons (Chls) that are tonically active. Dissecting the interactions between projection neurons and Chls is important for uncovering the role and mechanisms of the striatal microcircuits. Here, by combining several optogenetic tools with cell type-specific electrophysiological recordings, we uncovered direct electrical coupling between D1-type projection neurons and Chls, in addition to the chemical transmission between these two major cell types. Optogenetic stimulation or inhibition led to bilateral current exchanges between D1 neurons and Chls, which can be abolished by gap junction blockers. We further confirmed the presence of gap junctions through paired electrophysiological recordings and dye microinjections. Finally, we found that activating D1 neurons promotes basal activity of Chls via gap junctions. Collectively, these results reveal the coexistence of the chemical synapse and gap junctions between D1 neurons and Chls, which contributes to maintaining the tonically active firing patterns of Chls. Keywords: medium spiny neuron, tonically active neurons, electrical synapse, optogenetics, whole-cell patch,
motor learning

\section{INTRODUCTION}

As the main input nucleus of the basal ganglia, the striatum participates in motor control and goal-directed behavior (Abudukeyoumu et al., 2019). Dysfunctions of the basal ganglia are related to several neurological diseases, such as Parkinson's disease and Huntington's disease (Graybiel, 2000; Levine et al., 2011). Medium-sized spiny neurons (MSNs) comprise over 95\% of the striatal cell population (Kreitzer, 2009). MSNs are typically classified into two subpopulations containing neurons expressing dopamine D1 receptor subtypes or dopamine D2 receptor subtypes, which project to the globus pallidus interna $(\mathrm{GPi})$ and the substantia nigra pars reticularta (SNR) or the globus pallidus externa (GPe) (Gerfen, 1992; Lobo, 2009), respectively. Both types of projection neurons are GABAergic and inhibitory (Kreitzer, 2009). D1-MSNs also contain the peptide neurotransmitters dynorphin and substance P (SP, also known as tachykinin 1, Tac1), whereas D2-MSNs contain encephalin (Gerfen, 2000; Lobo et al., 2006). The remaining neurons consist of cholinergic interneurons (ChIs), and several different subtypes of GABAergic interneurons, such as NPY/SST/NOS interneurons, NPY-NGF (neurogliaform) interneurons, PV fast-spiking interneurons, TH interneurons, and CCK interneurons (Tepper et al., 2010; 
Ibanez-Sandoval et al., 2011; Assous et al., 2017; MunozManchado et al., 2018; Tepper et al., 2018). ChIs and SST neurons have been reported to express neurokinin-1 receptors (NK1R) in the striatum (Tuluc et al., 2009; Wang and Angulo, 2011).

ChIs represent a small population of striatal neurons (1-2\%) but exhibit broad arborizations in the striatum. ChIs exert a complex and powerful influence on the function of the striatum, such as co-releasing glutamate and acetylcholine to MSNs (Higley et al., 2011; Mamaligas and Ford, 2016), driving GABA release from dopaminergic terminals (Nelson et al., 2014), and triggering striatal DA release (Threlfell et al., 2012). ChIs are also referred to as tonically active neurons (TANs). They exhibit spontaneous tonic activity and respond to motivationally salient stimuli with a pause followed by a rebound increase, suggesting an important role of the basal tonic activation in their behavioral functions, including movement control and reward processing (Aosaki et al., 1995; Calabresi et al., 2000; Pisani et al., 2007; Goldberg and Reynolds, 2011; Cachope et al., 2012).

The exact microcircuitry between MSNs and ChIs remains unclear. MSNs might modulate the activity of ChIs through neurotransmitter release from chemical synapses. In addition to the chemical synaptic transmissions in the striatal microcircuits, electrical synapses (also known as gap junctions) are implicated in striatal neurons (Koós and Tepper, 1999; Venance et al., 2004; Cummings et al., 2008; English et al., 2011; Szydlowski et al., 2013). Gap junctions connect the cytosolic of two adjacent cells through a specialized channel constructed by two hemichannels (termed connexons). They allow the passage of small molecules up to $1,000 \mathrm{Da}$, which contributes to the generation of the synchronous activity (Kumar and Gilula, 1996; Sohl et al., 2005; Dere and Zlomuzica, 2012). It is unclear what kinds of cell types are electrically coupled in the striatum.

Here, we employed optogenetic tools to study the interaction between D1-MSNs and ChIs. In terms of optogenetic characters, channelrhodopsin-2 (ChR2) conducting cation-selective ion channel (Nagel et al., 2003; Boyden et al., 2005) and Lari with high-sequence homology to ArchT conducting proton (Han et al., 2011; Wu et al., 2019) were expressed in genetically identified D1-MSNs and ChIs. In addition to the chemical transmission, we found a slow current exchange between D1-MSNs and ChIs, which could be inhibited by gap junction blockers. In accordance with the optogenetic results, we also confirmed that D1-MSNs and ChIs are electrically coupled through paired electrophysiological recordings and dye microinjections. Furthermore, we found that activating D1-MSNs promotes the basal activity of ChIs, which can be decreased by bath application of gap junction blockers, indicating that D1-MSNs may contribute to the maintaining of the basal activity of ChIs through gap junctions.

\section{MATERIALS AND METHODS}

\section{Animals}

All procedures were conducted with the approval of the Animal Care and Use Committee of the National Institute of Biological Sciences, Beijing, in accordance with governmental regulations of China. We used 6-12-week-old male or female mice. ChATChR2-EYFP mice were gifts from G. Feng (MIT, Cambridge, MA, United States). Tac1-IRES-Cre (stock no: 021877), Ai32 mice (stock no: 012569), and SST-IRSE-Cre mice (stock no: 013044) were obtained from Jackson Laboratory (Bar Harbor, ME, United States). ChAT-Cre mice were obtained from Mutant Mouse Research and Resource Center (Davis, CA, USA). Wildtype C57BL6/N mice were purchased from VitalRiver (Beijing, China).

\section{AAV Virus Preparation and Injections}

AAV vectors carrying the fDIO-ChR2-EYFP, retro-Flp, DIOmCherry, DIO-mGFP, and fDIO-Lari-mRbuy3 were packaged into serotype $2 / 9$ vectors with titers $\sim 2 \times 10^{12}$ particles $/ \mathrm{ml}$. AAV2-fDIO-ChR2-EYFP and AAV2-retro-Flp were purchased from Shanghai Taitool Bioscience (Shanghai, China). The pAAVCAG-fDIO-Lari-mRbuy3 construct was a gift from Yulong Li's lab. The pAAV-EF1a-DIO-hChR2 (H134R)-mCherry construct was a gift from Karl Deisseroth (Addgene plasmid \#20297). We constructed these plasmids by replacing the coding region of ChR2-mCherry in the pAAV-EF1a-DIO-ChR2-mCherry plasmid with that of mGFP (Addgene plasmid \#14757).

For AAV injections, adult mice were anesthetized with pentobarbital (i.p. $80 \mathrm{mg} / \mathrm{kg}$ ) and then mounted to a stereotaxic apparatus. The craniotomy was conducted, and the recombinant AAV vectors were injected into the striatum (AP $0.74 \mathrm{~mm}$; ML $2.0 \mathrm{~mm}$; DV 2-4 mm) and the SNR (AP $34 \mathrm{~mm}$; ML $1.3 \mathrm{~mm}$; DV $4.4 \mathrm{~mm}$ ).

\section{Brain Slice Preparation}

We performed slice recordings as our laboratory previously described (Ren et al., 2011; Hu et al., 2012; Zhang et al., 2016). Briefly, adult mice were anesthetized with pentobarbital (i.p. $80 \mathrm{mg} / \mathrm{kg}$ ) and then transcardially perfused with $5 \mathrm{ml}$ ice-cold oxygenated perfusion solution. The perfusion solution contains reagents as follows (in millimolar): 225 sucrose, $119 \mathrm{NaCl}, 2.5$ $\mathrm{KCl}, 1 \mathrm{NaH}_{2} \mathrm{PO}_{4}, 4.9 \mathrm{MgCl}_{2}, 0.1 \mathrm{CaCl}_{2}, 26.2 \mathrm{NaHCO}_{3}, 1.25$ glucose, 3 kynurenic acid, and $1 \mathrm{Na}$-ascorbate. Next, the mouse brains were dissected and transferred into ice-cold oxygenated slice solution. The slice solution contains reagents as follows (in millimolar): 110 choline chloride, $2.5 \mathrm{KCl}, 0.5 \mathrm{CaCl}_{2}, 7$ $\mathrm{MgCl}_{2}, 1.3 \mathrm{NaH}_{2} \mathrm{PO}_{4}, 25 \mathrm{NaHCO}_{3}, 10$ glucose, $1.3 \mathrm{Na}$-ascorbate, and 0.6 Na-pyruvate. The slice solution was adjusted to 305$315 \mathrm{Osm} / \mathrm{kg}$ using sucrose. Sections containing the striatum (200 $\mu \mathrm{m}$ ) were cut with a vibratome (VT1200s, Leica Biosystems, Wetzlar, Germany) and then incubated in $33^{\circ} \mathrm{C}$ oxygenated artificial cerebrospinal fluid (ACSF) containing reagents as follows (in millimolar): $125 \mathrm{NaCl}, 2.5 \mathrm{KCl}, 2 \mathrm{CaCl}_{2}, 1.3 \mathrm{MgCl}_{2}, 1.3$ $\mathrm{NaH}_{2} \mathrm{PO}_{4}, 1.3 \mathrm{Na}$-ascorbate, $0.6 \mathrm{Na}$-pyruvate, 10 glucose, and 25 $\mathrm{NaHCO}_{3}$ (305-315 Osm/kg). All chemicals were purchased from Sigma-Aldrich (St. Louis, MO, United States).

\section{Patch Recording}

The recording pipettes (3-4 M $\Omega$ ) for whole-cell recordings and cell-attached recordings were pulled by P-1000 (Sutter Instrument, Novato, CA, United States). An internal solution filled in the recording pipettes contains reagents as follows (in 
millimolar): $130 \mathrm{~K}$-gluconate, $10 \mathrm{HEPES}, 0.6 \mathrm{EGTA}, 5 \mathrm{KCl}, 3$ $\mathrm{Na}_{2}$ ATP, $0.3 \mathrm{Na}_{3} \mathrm{GTP}, 4 \mathrm{MgCl}_{2}$, and $10 \mathrm{Na}_{2}$-phosphocreatine ( $\mathrm{pH} 7.2-7.4,295-305 \mathrm{Osm} / \mathrm{kg}$ ). Slice recordings were performed with MultiClamp700B (Molecular Devices, San Jose, CA, United States). The traces were low-pass filtered at $3 \mathrm{kHz}$ and digitized at $10 \mathrm{kHz}$ (Axon Digidata 1322A, Molecular Devices, San Jose, CA, United States). The electrophysiological data was analyzed with Clampfit 10.2 software (Molecular Devices, San Jose, CA, United States).

For optogenetic stimulation, an optical fiber $(0.2 \mathrm{~mm}$ core diameter, $\mathrm{NA}=0.22$ ) linked to a $473 \mathrm{~nm}$ laser driver (MBL-III-473, Changchun New Industries Optoelectronics Technology Co., Changchun, China) or a $561 \mathrm{~nm}$ laser driver (MXL-W-561, Changchun New Industries Optoelectronics Technology Co., Changchun, China) was submerged in ACSF and placed $\sim 0.3 \mathrm{~mm}$ from the recording site. The light intensity reaching the brain tissue was $0.2-10 \mathrm{~mW} / \mathrm{mm}^{2} ; 20 \mathrm{~Hz}-5 \mathrm{~s}$ ( $5 \mathrm{~ms}$ pulses) or $5 \mathrm{~s}$ continuous photostimulation was used in the whole procedure.

The drugs were applied through perfusion or local injection. Drugs used in the slice recordings were as follows: tetrodotoxin (TTX, $1 \mu \mathrm{M}$, Tocris Bioscience, Bristol, United Kingdom), a voltage-gated sodium channel blocker; picrotoxin $(50 \mu \mathrm{M}$, Sigma-Aldrich, St. Louis, MO, United States), a blocker of $\mathrm{GABA}_{\mathrm{A}}$ receptors; 6,7-dinitroquinoxaline-2,3-dione (DNQX, 10 $\mu \mathrm{M}$, Sigma-Aldrich, St. Louis, MO, United States), an AMPAtype glutamate receptor blocker; 2-amino-5-phosphonovalerate (APV, $50 \mu \mathrm{M}$, Sigma-Aldrich, St. Louis, MO, United States), an NMDA-type glutamate receptor blocker; SR140333 (10 $\mu \mathrm{M}$, Tocris Bioscience, Bristol, United Kingdom); FK888 hydrate (10 $\mu \mathrm{M}$, Sigma-Aldrich, St. Louis, MO, United States) and L-703606 oxalate salt hydrate (100 nM, Sigma-Aldrich, St. Louis, MO, United States), NK1R blockers; carbenoxolone disodium (CBX, $200 \mu \mathrm{M}$, Tocris Bioscience, Bristol, United Kingdom) and quinine (200 $\mu \mathrm{M}$, Sigma-Aldrich, St. Louis, MO, United States), gap junctions blockers; [Sar ${ }^{9}, \operatorname{Met}\left(\mathrm{O}_{2}\right)^{11}$ ]-substance P $(1 \mu \mathrm{M}$, Tocris Bioscience, Bristol, United Kingdom), a selective NK1R agonist; and substance P (5 $\mu \mathrm{M}$, Tocris Bioscience, Bristol, United Kingdom).

\section{Neurobiotin Microinjection}

Neurobiotin $(7.5 \mathrm{mg} / \mathrm{ml}$; Vector Laboratories, Burlingame, CA, United States) was dissolved into the internal solution. We employed whole-cell recordings to the neuron with the pipette filled with Neurobiotin. After electrophysiological characterization, neurons were held for at least $30 \mathrm{~min}$ in current clamp and constantly injected with a depolarization current ( $500 \mathrm{~ms}, 500 \mathrm{pA}, 1 \mathrm{~Hz}$ ) to allow Neurobiotin filling. Subsequently, slices were fixed overnight in $4 \%$ paraformaldehyde at $4^{\circ} \mathrm{C}$. Cy3conjugated streptavidin (Jackson ImmunoResearch Laboratories. Inc., West Grove, PA, United States) was used to visualize the Neurobiotin signals.

\section{Dual-Patch Recordings}

Dual whole-cell recordings were performed on pairs of a $\mathrm{ChI}$ neuron and a D1 neuron. The distance between two neurons never exceeded $50 \mu \mathrm{m}$. Current steps were applied to ChI (+800
pA and -800 pA, 1 s current steps) and then we recorded voltage responses in the D1 neuron. Voltage responses in the D1 neuron were analyzed with average traces from 10 sweeps.

\section{Immunohistochemistry}

Adult mice were anesthetized with an overdose of pentobarbital and then transcardially perfused with $4 \%$ paraformaldehyde (PFA). Mouse brain was dissected and fixed in $4 \%$ PFA for $4 \mathrm{~h}$. After cryoprotection in 30\% sucrose, brain sections (35 $\mu \mathrm{m}$ ) were cut on a cryostat microtome (Leica CM1950, Leica Biosystems, Wetzlar, Germany). After rinsing with PBS and $0.3 \%$ Triton-X in $0.1 \mathrm{M}$ PBS (PBST), the brain sections were blocked with $2 \%(w / v)$ bovine serum (BSA) in PBST for $1 \mathrm{~h}$. Then, the brain sections were incubated with primary antibodies at $4^{\circ} \mathrm{C}$ for $48 \mathrm{~h}$ and secondary antibodies at room temperature for $2 \mathrm{~h}$. Images were collected using a Zeiss LSM510 Meta or Nikon A1 confocal microscope and analyzed using FIJI. The antibodies used were as follows: anti-choline acetyltransferase (1:200, goat, AB144P, MERCK, Kenilworth, NJ, United States), anti-NK1R (S8305, rabbit, 1:5,000, SigmaAldrich, St. Louis, MO, United States), goat anti-rabbit for NK1R (Cy3 and Alexa Fluor 488, Jackson ImmunoResearch Laboratories, Inc., West Grove, PA, United States), donkey antigoat for choline acetyltransferase (Cy3 and Alexa Fluor 488, Jackson ImmunoResearch Laboratories, Inc., West Grove, PA, United States), and Cy3-streptavidin (1:500).

\section{Data Analysis}

All results were expressed as mean \pm SEM, and statistical significance was assessed with Student's $t$-test. ${ }^{* *} P<0.01$; ${ }^{* * *} P<0.001 ;{ }^{* * * *} P<0.0001$; and n.s., not significant for all statistical analyses are presented in figures. The strength of the gap junction coupling was quantified by calculating the coupling coefficient (CC) and correlation coefficient. Coupling coefficient was the ratio between the voltage deflections in the post- and pre-electrical synapse, and 10 sweeps were averaged as follows: $\mathrm{CC}(\%)=\left(\Delta V_{\text {post }-} / \Delta \mathrm{V}_{\text {pre- }}\right) \times 100$ (Hinckley and ZiskindConhaim, 2006). Correlation coefficient was calculated using MATLAB corrcoef function.

\section{RESULTS}

\section{Tetanic Photostimulation of Striatal D1 Neurons Induces a Typical Inward Current in Chls}

We used a dual-virus strategy to specifically label and manipulate striatal D1 neurons and ChIs (Gerfen, 1992; Guo et al., 2015; Li et al., 2018). Specifically, we injected retrograde transport-orientated adeno-associated virus (AAV) carrying recombinase flippase vector into the SNR and then injected AAV virus carrying flippase-dependent vector fDIO-ChR2EYFP into the striatum to express ChR2 in D1 neurons projecting to the SNR (Figures 1A,B). As expected, we found that ChR2-EYFP-expressing D1 neurons projected to the SNR (Tervo et al., 2016). We also injected AAV-DIO-mCherry 

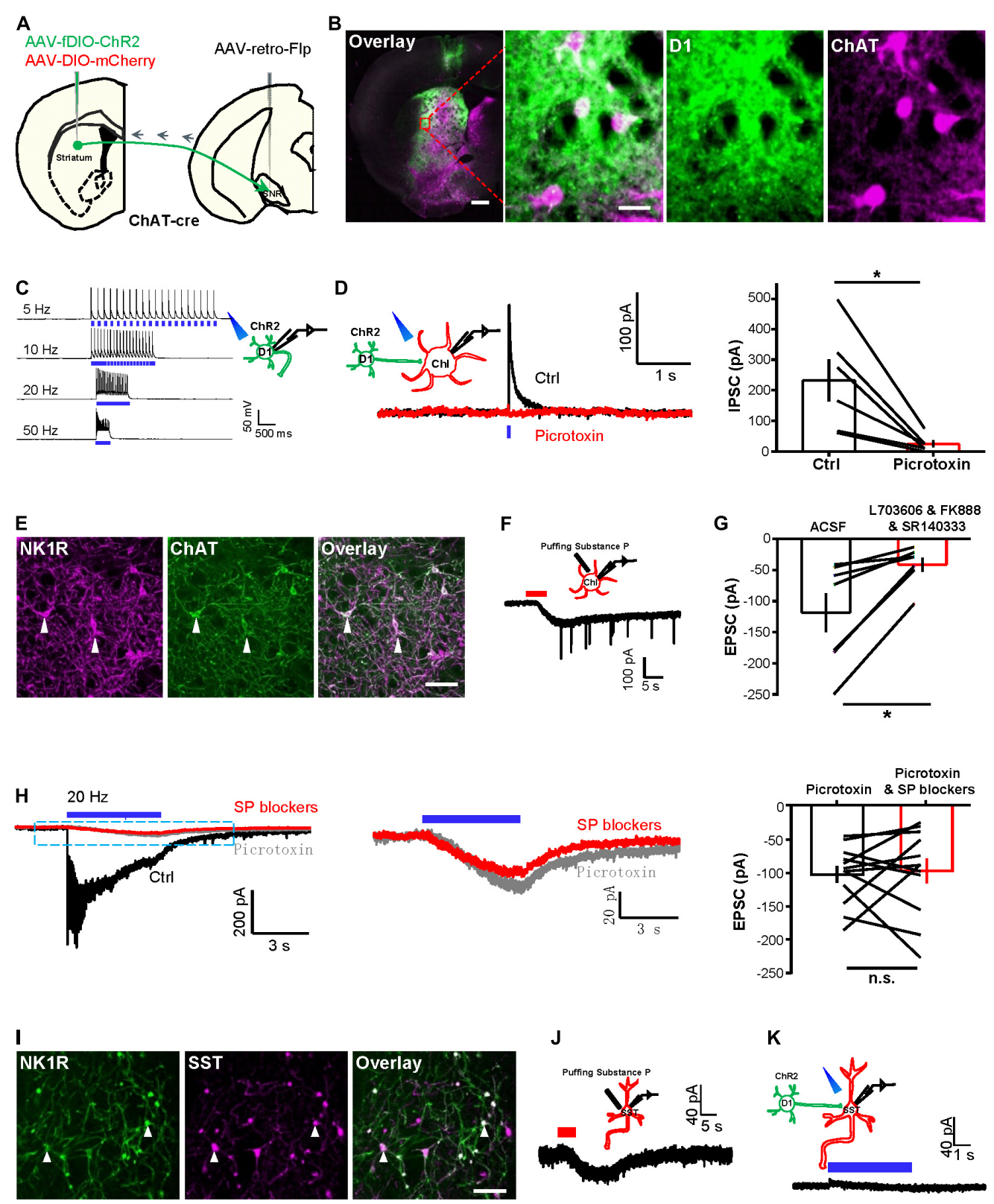

FIGURE 1 | Tetanic photostimulation of D1 neurons induces an inward current in Chl that could not be inhibited by SP blockers. (A) Schematic representation showing the injection of AAV2/2-retro-hSyn-Flpo into the substantia nigra pars reticulata (SNR) and of AAV-fDIO-ChR2-EYFP and AAV-DIO-mCherry into the striatum of a ChAT-Cre mouse. (B) Images showing the expression of virus in the striatum (left panel), scale bar $=500 \mu \mathrm{m}$. The zoom-in view of the dashed rectangular area, showing the specific expression of ChR2 in D1 neurons and the specific expression of mCherry in Chls (right panel). Green: D1 neurons with ChR2-EYFP; magenta: Chls with mCherry. Scale bars $=50 \mu \mathrm{m}$. (C) A schematic diagram showing the method of whole-cell recording of the ChR2-expressing D1 neuron by $470 \mathrm{~nm}$ stimulation. Trains of brief laser pulse at $5,10,20$, and $50 \mathrm{~Hz}(5 \mathrm{~ms}$ duration, $5 \mathrm{~mW}$ ) produced precise firing of action potentials $(n=7$ cells tested). (D) A schematic diagram and example traces (left) show brief optogenetic stimulation of ChR2-expressing D1 neurons produced a fast IPSC in Chl and the IPSC was inhibited by picrotoxin. The right panel shows group data. ${ }^{*} p<0.05$ (paired $t$-test; $n=7$ cells; ctrl: $231.6 \pm 68.6$ pA; mean \pm SEM; picrotoxin: $25.2 \pm 11.0$ pA; recorded at -10 $\mathrm{mV}$ ). (E) Images showing the specific expression of NK1R and ChAT in the striatum. White solid arrowheads indicated colocalized neurons. Scale bar $=100 \mu \mathrm{m}$. (F) A schematic diagram and example traces show that puffing $1 \mu \mathrm{M}\left[\mathrm{Sar}{ }^{9}, \operatorname{Met}\left(\mathrm{O}_{2}\right)^{11}\right]$-substance $\mathrm{P}$ evoked inward currents from Chls $(n=9$ cells; peak amplitude: $-75.1 \pm 14.5 \mathrm{pA}$ ). (G) The group data show the effect of the SP blockers cocktail on the response of Chls to the puffing of $5 \mu \mathrm{M}$ substance P. ${ }^{*} p<0.05$ (paired $t$-test; $n=7$ cells; ctrl: $-118.7 \pm 31.5$ pA; SP blockers: $-41.4 \pm 11.4$ pA). (H) Example traces (left and middle) show the effects of picrotoxin and the SP blockers cocktail of L703606, FK888, and SR14033 on (left panel) the currents evoked by tetanic stimulation $(20 \mathrm{~Hz}, 5 \mathrm{~ms}$ pulses, $5 \mathrm{~s}$ duration) of D1 neurons and recorded in a Chl. Summary data (right panel) show that the effects of SP blockers lack statistical significance. n.s., non-significant, $p>0.05$ (paired $t$-test; $n=12$ cells; ctrl: $-102.5 \pm 12.7 \mathrm{pA}$; SP blockers: $-97.0 \pm 18.6 \mathrm{pA}$ at $-65 \mathrm{mV}$ ). (I) Images show the expression of NK1R and SST in the striatum. White solid arrowheads indicated colocalized neurons. Scale bar $=200 \mu \mathrm{m}$. (J) A schematic diagram and example trace show the response of an SST neuron to the puffing of $1 \mu \mathrm{M}$ [Sar ${ }^{9}$, $\operatorname{Met}\left(\mathrm{O}_{2}\right)^{11}$ ]-substance $\mathrm{P}(n=5$ cells; peak amplitude: $-12.5 \pm 3.2 \mathrm{pA})$. (K) A schematic diagram and example trace show the lack of response of an SST neuron in response to $5 \mathrm{~s}$ continuous optogenetic stimulation of D1 cells in TTX solution ( $n=5$ cells; peak amplitude: $4.8 \pm 5.1 \mathrm{pA}$ at $-65 \mathrm{mV})$. 
into the striatum of ChAT-Cre mice and thereby successfully labeled ChIs (Figures 1A,B). Whole-cell recordings in slice preparations revealed that trains of brief laser pulses at different frequencies induced precise firing of action potentials of D1 neurons (Figure 1C; $n=7$ cells), confirming the validity of optogenetic stimulation.

We next examined the synaptic responses of ChIs to the photostimulation of ChR2-expressing D1 neurons. A brief light pulse induced fast inhibitory postsynaptic currents (IPSCs) in ChIs, and these were largely abolished upon the presence of the $\mathrm{GABA}_{\mathrm{A}}$ blocker picrotoxin (Figure 1D). These findings collectively established that ChIs receive GABAergic synaptic transmission from D1 neurons.

Given that D1 neurons contain neuropeptide SP (Gerfen, 2000; Lobo et al., 2006), we asked whether activating D1 neural terminals induces the release of SP to striatal ChIs. NK1R (also known as TACR1 and the SP receptor) was colocalized with ChIs and SST neurons in the striatum (Tuluc et al., 2009; Wang and Angulo, 2011). Immunostaining against NK1R confirmed that ChIs expresses NK1R (Figure 1E). Whole-cell patch recordings showed that the slow currents evoked by puffing $1 \mu \mathrm{M}\left[\mathrm{Sar}^{9}, \operatorname{Met}\left(\mathrm{O}_{2}\right)^{11}\right]-\mathrm{SP}$, a potent NK1R agonist (Blomeley and Bracci, 2008; Sosulina et al., 2015), exhibited a peak amplitude of $-75.1 \pm 14.5 \mathrm{pA}$ (Figure 1F; mean \pm SEM; $n=9$ cells). Furthermore, the SP currents were inhibited (by 65\%) upon perfusing a cocktail of SP blockers comprising SR140333 (Emonds-Alt et al., 1993; Huang et al., 2010), FK888 (Ferreira et al., 2005; Andrade et al., 2008), and L-703606 (Ikeda et al., 2003; Robinson et al., 2012; Figure 1G). These results thus demonstrate that the NK1Rs on ChIs are functional. Given that a brief pulse evoked fast IPSCs that were mediated through $\mathrm{GABA}_{\mathrm{A}}$ receptors, we tested whether SP could be released by tetanic stimulation of D1 neurons. We found that a $20 \mathrm{~Hz}-5 \mathrm{~s}$ stimulation of D1 neurons induced slow inward currents on ChIs (Figure 1H, left panel). However, the application of SP blockers did not significantly reduce the inward currents (Figure $\mathbf{1 H}$ ), and the remaining slow inward currents exhibited a mean amplitude of $-97.0 \pm 18.6 \mathrm{pA}$ isolated with picrotoxin and SP blockers, suggesting that they were not secondary to the released SP. Similarly, we found that SST neurons express NK1R (Figure 1I) and were activated by puffing $1 \mu \mathrm{M}\left[\operatorname{Sar}^{9}, \operatorname{Met}\left(\mathrm{O}_{2}\right)^{11}\right]$-SP with a mean amplitude of $-12.5 \pm 3.2 \mathrm{pA}$ (Figure 1J; $n=5$ cells). However, tetanic stimulation ( $5 \mathrm{~s}$ continuous) of D1 neurons did not induce slow inward currents on SST neurons (Figure 1K). Together, these results revealed that tetanic photostimulation of striatal D1 neurons induces an inward current in ChI that could not be inhibited by SP blockers.

We then studied the nature of the slow inward currents in ChIs in response to the tetanic stimulation of D1 neurons. We confirmed that $20 \mathrm{~Hz}-5 \mathrm{~s}$ stimulation of ChR2-expressing D1 neurons or ChIs generated precise firing of action potentials, and $5 \mathrm{~s}$ continuous stimulation of ChR2-expressing D1 neurons or ChIs generated action potential firings in the current-clamp recording mode and induced inward currents in the voltageclamp recording mode (Figures 2A-D). TTX-a voltage-gated sodium channel blocker-significantly disrupted action potential firing of D1 neurons and inhibited the fast IPSCs on ChIs induced by a brief light pulse stimulation of D1 neurons (Figure 2E; $n=9$ cells), indicating the requirement of action potentials to induce synaptic transmission. However, the slow inward currents of ChIs evoked by $20 \mathrm{~Hz}-5 \mathrm{~s}$ stimulation of $\mathrm{D} 1$ neurons were still detected when using the TTX solution or a TTX and nominally $\mathrm{Ca}^{2+}$-free extracellular solution, with peak amplitudes of $-170.2 \pm 27.6 \mathrm{pA}(n=9$ cells $)$ and $-219.0 \pm 15.9 \mathrm{pA}(n=5$ cells), respectively (Figures 2 F,G). These results suggest that the slow inward currents of ChIs are independent of action potential firing and of $\mathrm{Ca}^{2+}$ influx.

We tested whether changing the ion concentrations of ACSF affects the slow inward currents of ChIs. A low-concentration sodium solution $\left(28 \mathrm{mM} \mathrm{Na}^{+}\right)$reversibly reduced the amplitudes of slow inward currents of ChIs evoked by $5 \mathrm{~s}$ continuous stimulation of ChR2-expressing D1 neurons (Figure 2H,I; $n=7$ cells), demonstrating that sodium entry through ChR2 channels in D1 neurons is necessary for the generation of the slow inward currents of ChIs.

A recent study reported that light-driven temperature changes can affect striatal MSNs firing rates, specifically through inwardly rectifying potassium channels (Owen et al., 2019). We found that the slow inward currents were unaffected in ChIs recorded using a cesium-based internal solution, which excluded the role of potassium channels in the slow inward currents (Figure 2J; $n=6$ cells; peak amplitude: $-154.1 \pm 66.4 \mathrm{pA}$ ) (Owen et al., 2019). Moreover, we labeled D1 neurons with GFP and then performed whole-cell recordings from ChIs with constant light delivery at $470 \mathrm{~nm}$ : light delivery induced a small outward current of ChIs rather than inward current (Figure 2K; $n=7$ cells), excluding the role of light-driven temperature changes in our case. Collectively, these results reveal that tetanic stimulation of D1 neurons produces both fast GABAergic neurotransmission and a slow SP-independent current in ChIs. As the slow inward currents between D1 neurons and ChIs were independent of action potential firing and of $\mathrm{Ca}^{2+}$ influx and were not caused by light-driven temperature effect, we hypothesized that the slow currents of ChIs responding to light delivery could arise from ions influx of optogenetic channels through gap junction channels (Wang et al., 2014).

\section{Gap Junctions Connect D1 Neurons and Chls}

We provided several additional lines of experimental evidence to demonstrate the existence of gap junctions between D1 neurons and ChIs. First, we tested the effect of the gap junction blocker CBX (Ross et al., 2000; Morita et al., 2007; Beck et al., 2008; Behrens et al., 2011; Benedikt et al., 2012; ManjarrezMarmolejo and Franco-Pérez, 2016; Spray et al., 2019). CBX (200 $\mu \mathrm{M})$ reduced the amplitudes of slow inward currents by $71.1 \%$ (Figure 3A; $n=8$ cells). Second, we showed that the connections between D1 neurons and ChIs conduct bidirectional connection, a typical property of gap junction channels. We expressed ChR2 in ChIs and recorded from fluorescently labeled D1 neurons. Indeed, we found that there were small slow currents on D1 neurons during $5 \mathrm{~s}$ continuous activation of ChIs in TTX solution (Figure 3B; $n=18$ cells; peak amplitude: $-28.7 \pm 3.3 \mathrm{pA}$ ). 

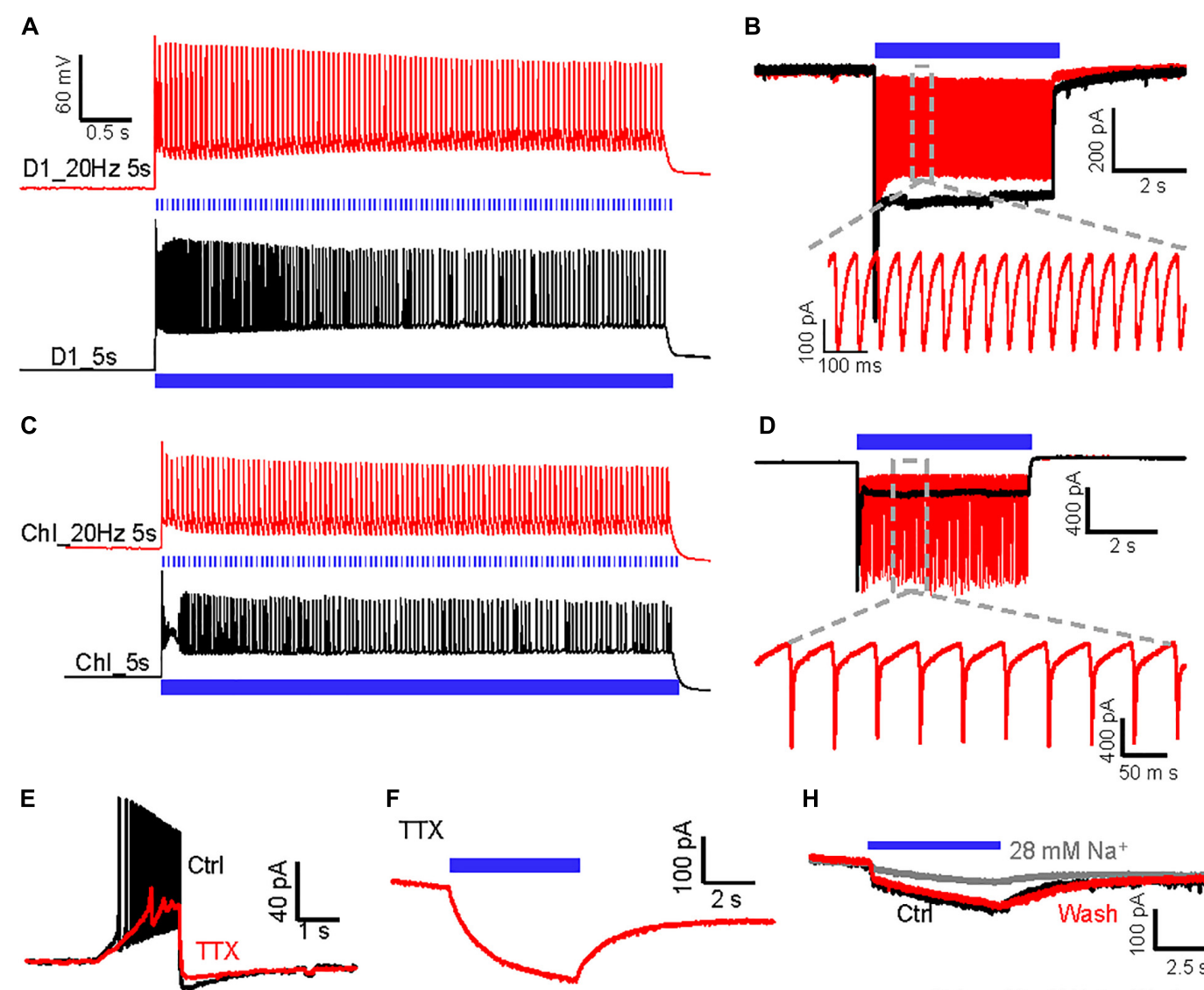

$\mathbf{F}$

H
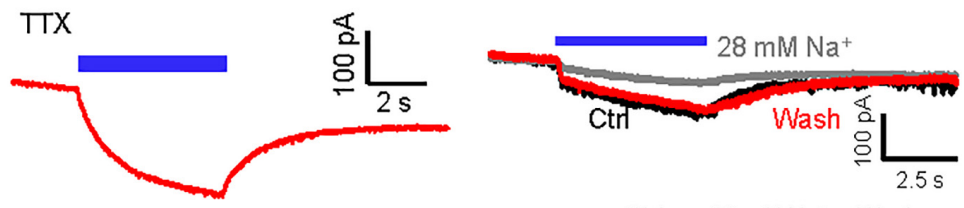

G

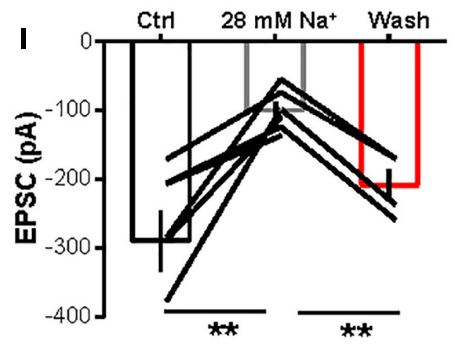

$\mathbf{J}$
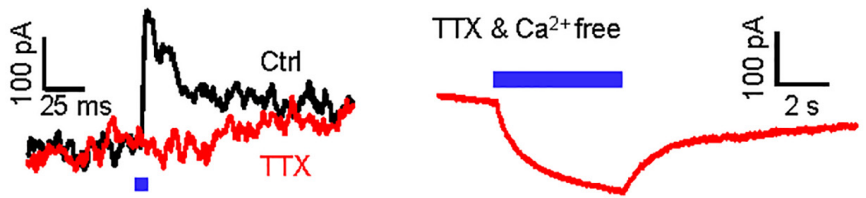

K
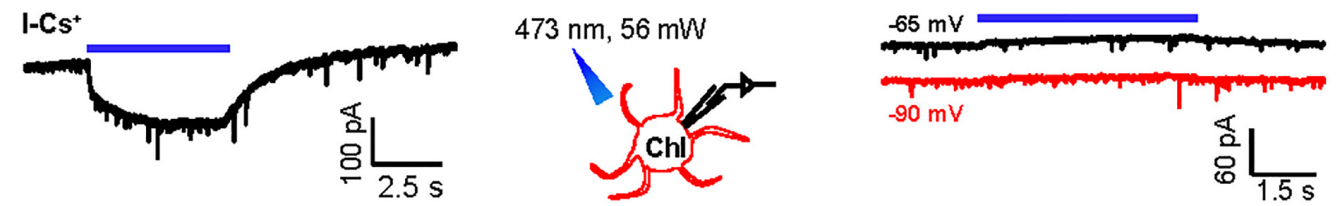

FIGURE 2 | The slow inward currents induced by activation of D1 neurons are independent of action potential firing and extracellular $\mathrm{Ca}^{2+}$. (A,B) A schematic diagram showing the method of whole-cell recording of the ChR2-expressing D1 neuron by $470 \mathrm{~nm}$ stimulation in the current-clamp mode (A) and voltage-clamp mode (B). Trains of tetanic stimulation laser pulse at $20 \mathrm{~Hz}-5 \mathrm{~s}(5 \mathrm{~ms}$ duration, $5 \mathrm{~mW}$, red line) and $5 \mathrm{~s} \mathrm{continuous} \mathrm{(black} \mathrm{line)} \mathrm{produced} \mathrm{tetanic} \mathrm{firing} \mathrm{of} \mathrm{action}$ potentials (A) and inward currents (B) $(n=10$ cells tested). (C,D) A schematic diagram showing the method of whole-cell recording of the ChR2-expressing Chl by $470 \mathrm{~nm}$ stimulation in the current-clamp recording mode (C) and voltage-clamp recording mode (D). Trains of tetanic stimulation laser pulse at $20 \mathrm{~Hz}-5 \mathrm{~s}(5 \mathrm{~ms}$ duration, $5 \mathrm{~mW}$, red line) and $5 \mathrm{~s}$ continuous (black line) produced tetanic firing of action potentials (C) and inward currents (D) ( $n=6$ cells tested). (E) Effect of TTX on the firing of action potentials following 100 pA inward current injection into a Chl (upper) and the fast IPSC evoked by a brief photostimulation of D1 neurons $(n=9$ Chls). (F,G) The slow inward current in a Chl evoked by $20 \mathrm{~Hz}-5 \mathrm{~s}$ stimulation of D1 neurons in the presence of $T \mathrm{TX}[(\mathbf{F}) ; n=9$ cells; peak amplitude: $-170.2 \pm 27.6 \mathrm{pA}$; at $-90 \mathrm{mV}]$ and TTX and $\mathrm{Ca}^{2+}$-free solution $[(\mathbf{G}) ; n=5$ cells; peak amplitude: $-219.0 \pm 15.9 \mathrm{pA}$; at $-90 \mathrm{mV}]$. $(\mathbf{H}, \mathbf{l})$ Example traces $(\mathbf{H})$ and group data (I) show the effect of reducing extracellular $\mathrm{Na}^{+}$concentration to $28 \mathrm{mM}$ on the inward currents in the Chl in response to $5 \mathrm{~s}$ continuous optogenetic stimulation of the ChR2-expressing D1 neurons in the presence of TTX. ${ }^{* *} p<0.01$ (paired $t$-test; $n=7$ cells; ctrl: $-289.6 \pm 43.4$ pA; $28 \mathrm{mM} \mathrm{Na}{ }^{+}:-99.7 \pm 12.6 \mathrm{pA}$; wash: $-208.7 \pm 22.9$ pA). (J) In TTX solution, 5 s continuous optogenetic stimulation of D1 neurons continued to evoke a slow inward current in a Chl recorded with a Cs ${ }^{+}$-based internal solution ( $n=6$ cells; peak amplitude: $-154.1 \pm 66.4$ pA). (K) $5 \mathrm{~s}$ continuous stimulation ( $470 \mathrm{~nm}, 56 \mathrm{~mW}$ power) produced a slow outward current in an mCherry-expressing Chl neuron held at -65 and $-90 \mathrm{mV}$ in the presence of $\Pi \mathrm{X}(n=7 \mathrm{Chl}$ cells; peak amplitude at $-65 \mathrm{mV}$ : $33.4 \pm 9.5 \mathrm{pA}$; peak amplitude at $-90 \mathrm{mV}: 18.9 \pm 9.5 \mathrm{pA})$. 

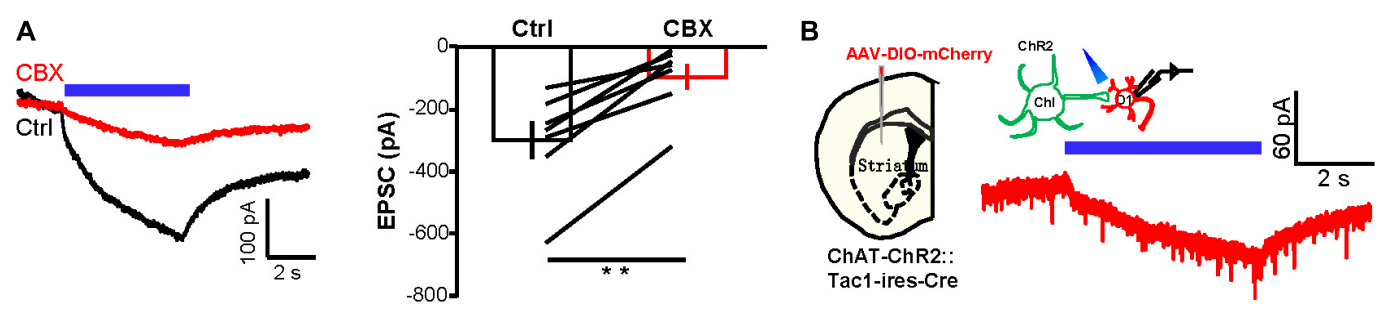

FIGURE 3 | CBX substantially suppresses the current exchange between D1 neurons and Chls. (A) Example traces and group data show the effect of CBX (200 $\mu \mathrm{M}$ ) on the inward current of Chls in response to $5 \mathrm{~s}$ continuous optogenetic stimulation of D1 neurons in the presence of $T \mathrm{TX}$. ${ }^{* \star} p<0.01$ (paired $t$-test; $n=7$ cells; ctrl: $-299.2 \pm 61.5$ pA; CBX: $-95.7 \pm 41.0$ pA). (B) Schematics and example traces showing that $5 \mathrm{~s}$ continuous stimulation of Chls evoked a slow inward current in a D1 neuron from a AAV-DIO-mCherry-injected ChAT-ChR2-EYFP:Tac1-ires-Cre mouse in the presence of TTX ( $n=18$ D1 cells; peak amplitude: $-28.7 \pm 3.3$ pA).

\section{A}

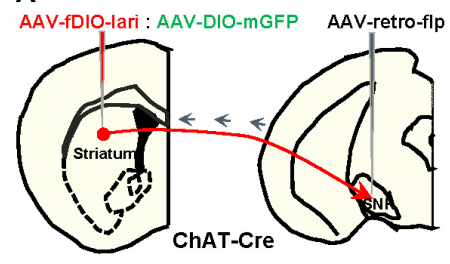

C
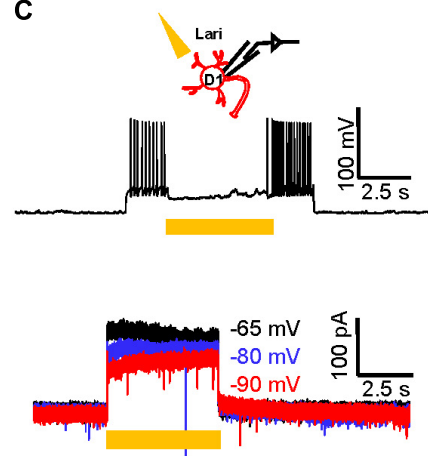
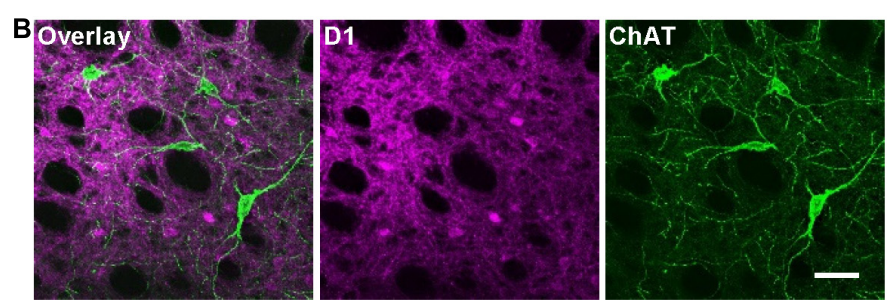

D
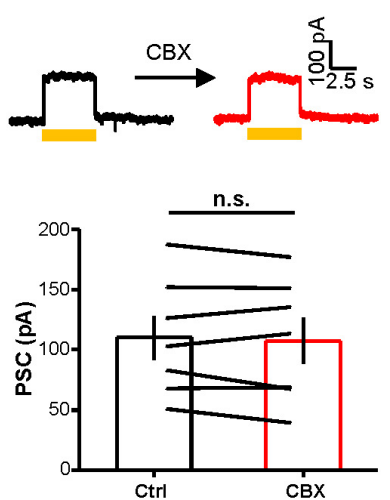

E
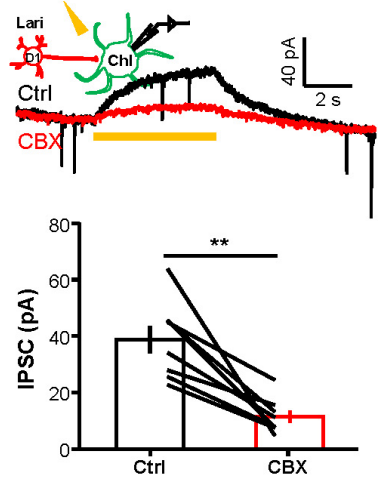

FIGURE 4 | Optogenetically evoked outward currents in D1 neurons induce CBX-sensitive outward current in Chls. (A,B) Schematics (A) and images (B) show the method and expression pattern of labeling D1 cells with Lari-mRuby3 and Chls with mGFP. Scale bar $=50 \mu \mathrm{m}$. (C) $5 \mathrm{~s}$ continuous stimulation (561 nm, $10 \mathrm{~mW}$ ) suppressed the action potential firing of a Lari-expressing D1 neuron and generated outward currents of various amplitudes at the holding potential of $-65,-80$, and $-90 \mathrm{mV}(n=7$ cells). (D,E) CBX (200 $\mu$ M) did not affect the optogenetically evoked outward currents in Lari-expressing D1 neurons [(D); n.s., non-significant; paired $t$-test; $n=7$ cells; ctrl: $110.0 \pm 18.4$ pA; CBX: $107.5 \pm 19.1 \mathrm{pA}$ ] but significantly suppressed the TTX-resistant outward currents recorded from nearby Chls [(E); ${ }^{* *} p<0.01 ;$ paired $t$-test; $n=8$ cells; ctrl: $\left.38.7 \pm 4.9 \mathrm{pA} ; \mathrm{CBX}: 11.4 \pm 2.2 \mathrm{pA}\right]$

Third, we used an optogenetic approach to demonstrate that inhibiting currents could also pass from D1 neurons to ChIs. We expressed Lari in D1 neurons and recorded from ChIs (Figures 4A,B). Lari is a light-driven outward proton pump and enables Lari-expressing neurons to be efficiently silenced in response to light stimulation (Wu et al., 2019). Neural action potentials of D1 neurons were effectively suppressed by $5 \mathrm{~s}$ continuous light $(561 \mathrm{~nm})$ under the current-clamp mode and generated outward currents in response to the different holding potentials in voltage-clamp recordings (Figure 4C; $n=7$ cells), results collectively supporting that $561 \mathrm{~nm}$ laser stimulation reliably opens this proton pump. We then performed wholecell recordings of ChIs during stimulation of Lari-expressing D1 neurons: whereas the outward currents in Lari-expressing D1 neurons were not obviously affected by CBX (Figure 4D; $n=7$ cells), the outward currents of ChIs were inhibited by $67.7 \%$ in the presence of CBX (Figure 4E; $n=8$ cells).

Fourth, we conducted dual-patch recordings to confirm the presence of gap junctions between D1 neurons and ChIs. By labeling D1 neurons with DIO-mCherry and labeling ChIs with ChR2-EYFP in ChAT-ChR2-EYFP:Tac1-ires-Cre mice, we were able to record D1 neurons and ChI cell pairs simultaneously (Figure 5A). We applied a blocker cocktail comprising DNQX, APV, SR140333, and picrotoxin to isolate the gap junctions. Under current-clamp conditions, depolarization of the ChI by +800 pA current injection induced a simultaneous depolarization of D1 neuron. About 44\% ChI-D1 neuron pairs ( $n=20 / 45$ pairs) were found to be electrically coupled, and 

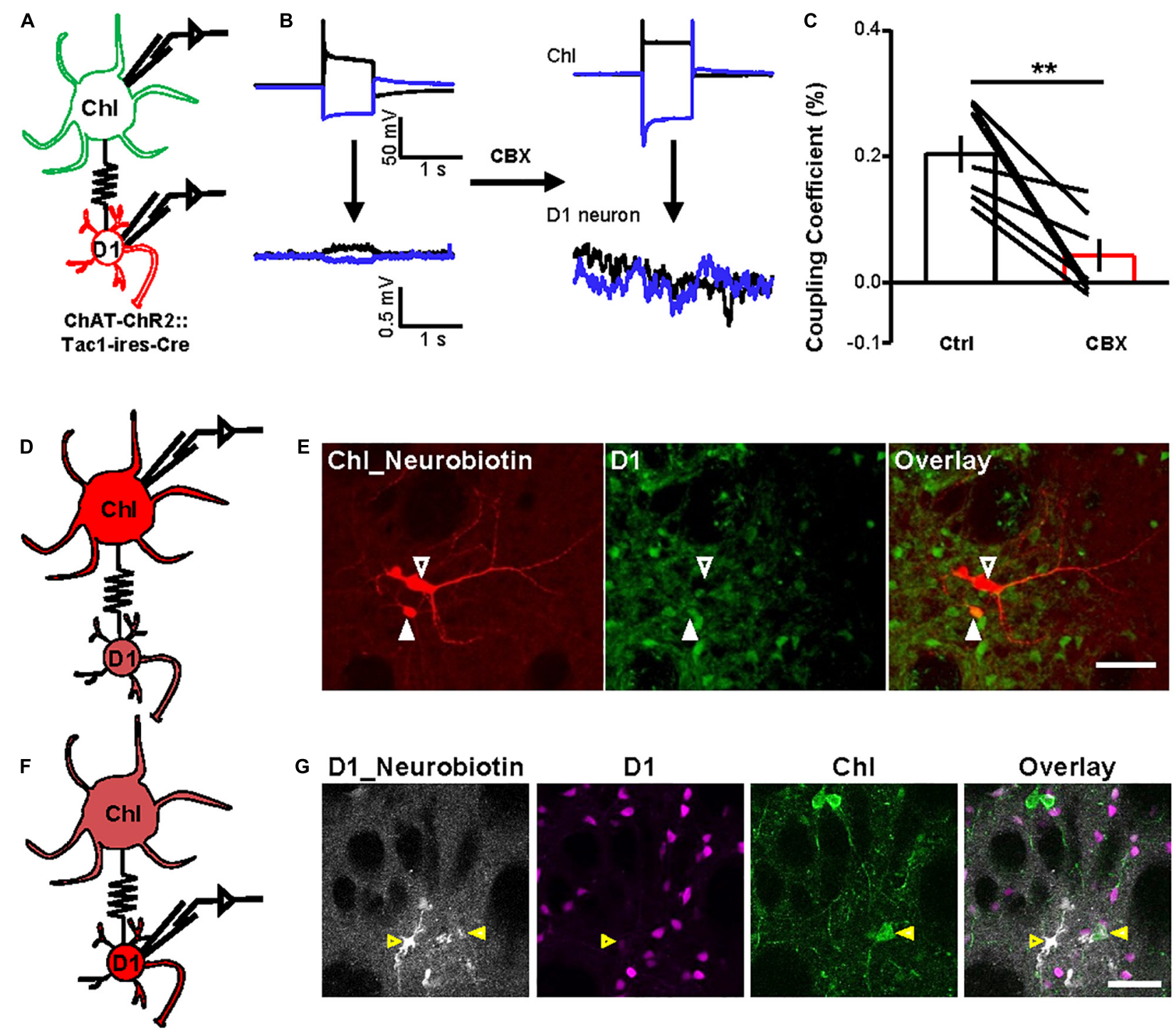

FIGURE 5 | Dual-patch recording and dye microinjection reveal gap junctions between Chls and D1 neurons. (A) A schematic diagram show the dual-patch recordings from a Chl-D1 neuron pair. (B,C) Current steps were applied to Chls $(-800$ and +800 pA, 1 s current steps) and then the voltage responses of D1 neuron were recorded (average traces from 10 sweeps). Example trace shows the blockade of electrical coupling by $200 \mu \mathrm{M}$ CBX (B). Summary data shows the coupling coefficient induced by depolarization of Chl was significantly reduced by $200 \mu \mathrm{M}$ CBX (C). ${ }^{* *} p<0.01$ (paired $t$-test; $n=7$ coupled Chl-D1 pairs; ctrl: coupling coefficient by depolarization: $0.3 \pm 0.03 \%$; CBX: coupling coefficient by depolarization: $0.04 \pm 0.02 \%)$. We also calculated the correlation coefficient of the coupled D1-Chls pairs (ctrl: correlation coefficient by depolarization: $0.66 \pm 0.04$; CBX: correlation coefficient by depolarization: $0.24 \pm 0.08$; ctrl: correlation coefficient by hyperpolarization: $0.64 \pm 0.03$; CBX: correlation coefficient by hyperpolarization: $0.23 \pm 0.09)$. (D,E) Schematics (D) and images (E) show that the Neurobiotin loaded into a Chl by whole-cell recording was detected in D1 neurons and other cell types. In (E), red indicates Neurobiotin visualized with Cy3-streptavidin and green indicates mGFP in D1 neurons. Open arrowhead indicates a Chl filled with Neurobiotin and the solid arrowhead indicate Neurobiotin-labeled D1 cell ( $n=8 / 10$ Chls; one Chl coupled with $2.5 \pm 0.5$ D1 neurons). Scale bar $=50 \mu \mathrm{m}$. (F,G) Schematics (F) and images (G) show that the Neurobiotin loaded into a D1 neuron by whole-cell recording was detected in Chl. In (G), gray indicates Neurobiotin visualized with Alexa Fluor ${ }^{\circledR} 647$ streptavidin conjugates, magenta indicates mscarlet in D1 neurons, and green indicates EYFP in Chl. Open arrowhead indicates a D1 neuron filled with Neurobiotin and the solid arrowhead indicates Neurobiotin-labeled Chl ( $n=2 / 20$ D1 neurons). Scale bar $=50 \mu \mathrm{m}$.

these coupled pairs displayed a mean coupling coefficient of $0.3 \%$ (Figure 5B). CBX significantly inhibited the coupling coefficient of the ChI-D1 cell pairs induced by depolarization of the ChI by 79.0\% (Figures 5B,C; $n=7$ pairs).

Finally, we injected small molecules to assess the occurrence of gap junctional communication between ChIs and D1 neurons.
We loaded Neurobiotin into a ChI during whole-cell recordings and examined Neurobiotin diffusion into mGFP-expressing D1 neurons (Figure 5D): somata, dendrites, and axons of recorded ChIs were clearly labeled with Neurobiotin (Figure 5E; $n=8 / 10$ ChIs). Each Neurobiotin-containing ChI showed tracer coupling to an average of 2.5 D1 neurons (Figure 5E). 
We also loaded Neurobiotin into a D1 neuron and observed Neurobiotin diffusion into ChIs (Figures 5F,G). These results thus collectively demonstrated that striatal D1 neurons and ChIs form gap junctions.

\section{Activating D1 Neurons Promotes Basal Activity of Chls via Gap Junctions}

Previous studies have suggested that striatal ChIs exhibit spontaneous tonic activity (Aosaki et al., 1995; Goldberg and
Reynolds, 2011). Given that ChIs receive inhibitory chemical synaptic inputs from D1 neurons, we hypothesized that the gap junctions between D1 neurons and ChIs may contribute to the basal activities of ChIs. Pursuing this, we performed cell-attached recordings from ChIs to assess whether D1-ChI neural gap junctions contribute to the basal activity of ChIs (Figure 6A). Stimulation of D1 neurons with $20 \mathrm{~Hz}-5 \mathrm{~s}$ trains increased ChI firing rates, from 1.8 to $4.3 \mathrm{~Hz}$ (ctrl: $1.8 \pm 0.6 \mathrm{~Hz}$; activation: $4.3 \pm 1.5 \mathrm{~Hz} ; n=8$ cells), upon the presence of a blocker cocktail solution comprising DNQX, APV, SR140333, and picrotoxin

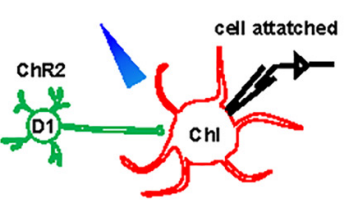

B

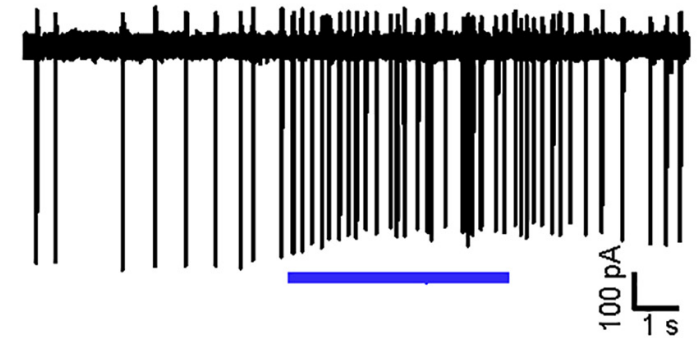

D
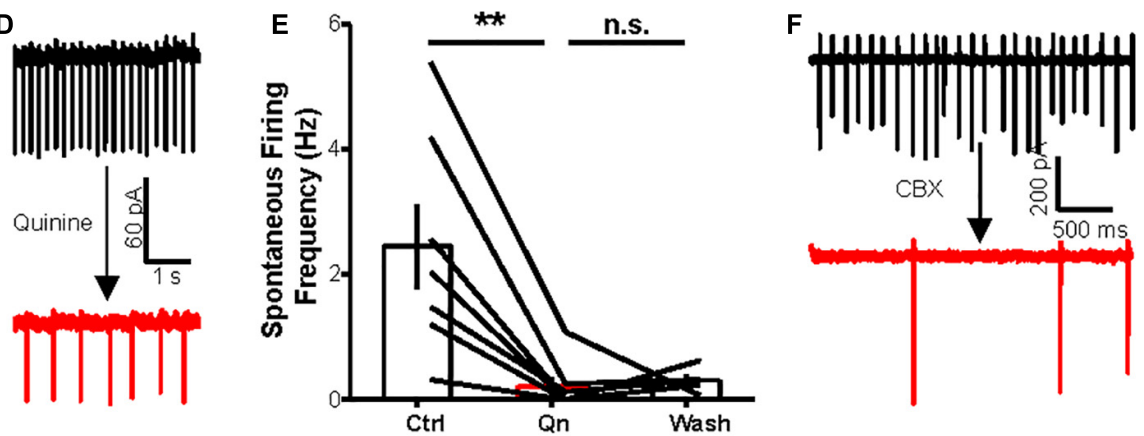
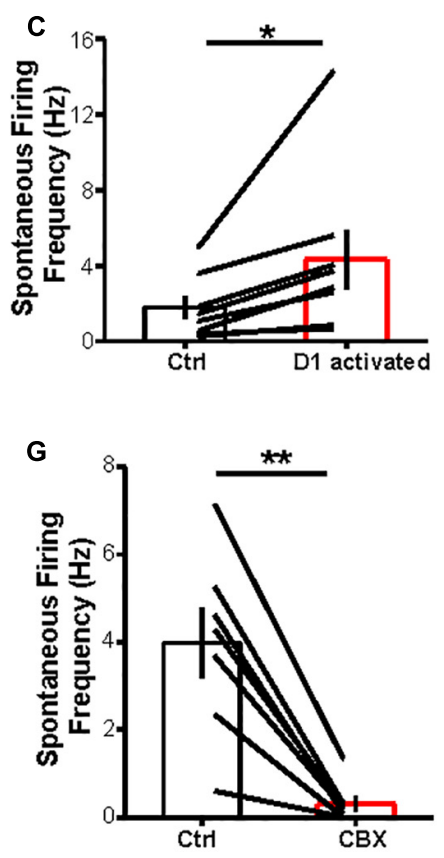

H

- GABA

- Substance P

-Nin- Gap junction

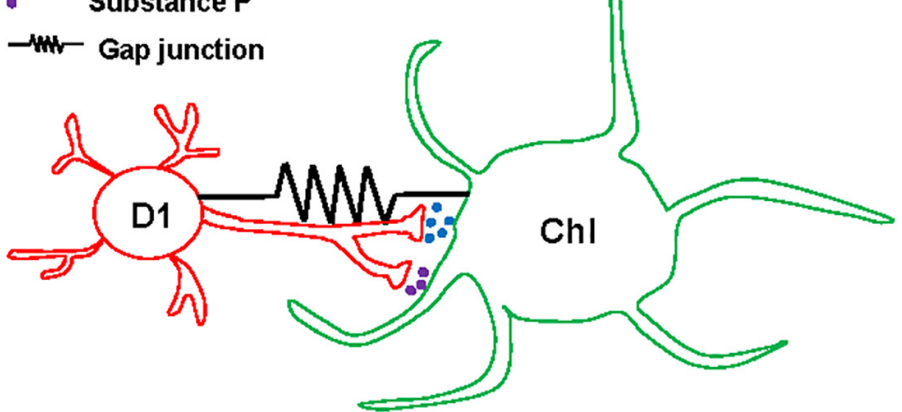

FIGURE 6 | Activating D1 neurons promotes basal activity of Chls via gap junctions. (A) Schematics show the method of cell-attached recording from a Chl and optogenetic stimulation of D1 cells (20 Hz-5 s light pulses). (B,C) An example trace (B) and summary data (C) show that optogenetic stimulation of D1 neurons enhanced the firing rates of Chls in the presence of a cocktail solution comprising DNQX, APV, SR140333, and picrotoxin to block the release of major neurotransmitters in the striatum. In (C), ${ }^{*} p<0.05$ (paired $t$-test; $n=8$; ctrl: $1.8 \pm 0.6 \mathrm{~Hz}$; activation: $4.3 \pm 1.5 \mathrm{~Hz}$ ). (D,E) Example traces (D) and the group data (E) show that quinine $(200 \mu \mathrm{M})$ suppressed the basal firing rates of Chls. ${ }^{* *} p<0.01$ (paired $t$-test; $n=7$ cells; ctrl: $2.5 \pm 0.7 \mathrm{~Hz}$; quinine: $0.2 \pm 0.2 \mathrm{~Hz}$; wash: $0.3 \pm 0.1 \mathrm{~Hz}) .(\mathbf{F}, \mathbf{G})$ The effect of CBX $(200 \mu \mathrm{M})$ on the basal firing rates of a representative neuron $(\mathbf{F})$ and the entire test group of Chls $(\mathbf{G})$. ${ }^{\star \star} p<0.01$ (paired $t$-test; $n=7$ cells; ctrl: $4.0 \pm 0.8 \mathrm{~Hz}$; CBX: $0.3 \pm 0.2 \mathrm{~Hz}$ ). (H) A diagram illustrates the interaction between D1 cells and Chls via both chemical synapses and electrical synapses. D1 cells modulate the activity of Chls through the release of GABA and substance P via chemical synapses. D1 cells and Chls are also electrically coupled via gap junctions. 
(Figures 6B,C), thus demonstrating that stimulating D1 neurons could increase the firing activity of ChIs through electrical coupling. In the slice preparation, ChIs exhibited tonic action potential firing, which is reminiscent of the tonic activation in vivo (Aosaki et al., 1995; Goldberg and Reynolds, 2011; Cachope et al., 2012). More importantly, the spontaneous firing rates of ChIs were inhibited by $90 \%$ following the bath application of gap junction blocker quinine (Figures 6D,E; $n=7$ cells). Consistent with the effect of quinine, CBX also significantly reduced the basal activity of ChIs (Figures 6F,G; $n=7$ cells). Collectively, these results suggest that the activity of D1 neurons drives enhanced basal activity of ChIs via gap junctions.

\section{DISCUSSION}

Combining optogenetics, paired electrophysiological recordings, and dye microinjections, here we report that striatal D1-MSNs interact with ChIs via both chemical synapses (through GABA release) and gap junctions (Figure $\mathbf{6 H}$ ). Moreover, the gap junctions promote the basal activity of ChIs, the tonic activation pattern of which is considered important for $\mathrm{ChI}$ functions. Our results thus shed light on the mechanism of cholinergic functions in modulating striatal output signals.

We provide multiple lines of evidences to support the presence of gap junctions between D1-MSNs and ChIs. First, optogenetically induced inward currents or outward currents in D1 cells or ChIs bidirectionally pass between these two types of neurons. Second, this current exchange is suppressed by gap junction blockers but is resistant to various blockers of chemical neurotransmission. Third, dual whole-cell recordings of D1 cell and ChI pairs reveal that electrically evoked currents pass two individual cells and again this passage is blocked by gap junction blockers. Finally, dye microinjections in individual $\mathrm{ChI}$ spread to nearby cells, including D1 cells. These experimental results together provide compelling support to our conclusion that D1-MSNs and ChIs are electrically coupled, in addition to our data that confirm D1-MSNs release neurotransmitters onto ChIs. Interestingly, we do not observe such electrical coupling between D1 cells and somatostatin-expressing interneurons, which suggests cell type specificity for electrical coupling among striatal neurons.

It was previously held that gap junctions decrease markedly upon neural maturity (Pereda, 2014). However, in adult mammals, gap junctions still coexist with chemical synapses between neurons (Lefler et al., 2014; Lapato and TiwariWoodruff, 2018). This trend is especially evident in the striatum, where MSNs are reported to be both electrically and chemically coupled (Venance et al., 2004), although it had remained unknown whether projection neurons and interneurons are electrically coupled. Usually, electrical and dye coupling between neurons is often restricted to cells of the same class (Galarreta and Hestrin, 2001; Hormuzdi et al., 2004; Vandecasteele et al., 2007), but several examples of gap junctions between different types of neurons have been well documented. Previous studies suggest heterosynaptic electrotonic coupling between NGFs and THINs in the striatum (Assous et al., 2017; Tepper et al.,
2018; Assous and Tepper, 2019). In the neocortex, there are electric synapses between SST interneurons and NPY-NGF interneurons, between SST interneurons and regular-spiking spiny stellate cells (putative excitatory neurons), and between fusiform interneurons and spiny stellate cells (Venance et al., 2000; Galarreta and Hestrin, 2001; Simon et al., 2005; UrbanCiecko and Barth, 2016). Gap junctions between neurons and astrocytes have also been reported (Nedergaard, 1994; AlvarezMaubecin et al., 2000). Taken together, although homologous electrical coupling is common, heterologous electrical coupling also exists, which may contribute to recruitment of neural network dependent on specific states and boost their efficacy in neural activity propagation.

Optogenetic manipulations enabled us to detect obvious electrical coupling between D1 cells and ChIs. Dual whole-cell recordings reveal that the coupling coefficients between D1-ChIs are small. There are two possibilities to explain why the coupling ratio of between D1 MSNs and ChIs is small. First, the coupling ratio will decrease following age increase (Meyer et al., 2002). For example, the coupling ratio in basket cell pairs detected in P14 is about 2.5\%, while that detected in P42 brain slices is about $1.2 \%$ (Meyer et al., 2002). Most of previous studies (including Koós and Tepper, 1999) recorded from animals younger than 42 days old (Koós and Tepper, 1999; Meyer et al., 2002; Hormuzdi et al., 2004; Simon et al., 2005), while our study used adult mice. Second, coupling ratio of heterologous gap junctions is usually smaller than that of homologous gap junctions (Meyer et al., 2002; Simon et al., 2005). We speculate that multiple D1-MSNs may be connected to one ChI via gap junctions, a scenario that would enable amplification of $\mathrm{ChI}$ responses to electrical transmission during stimulation of optogenetic channel-expressing D1-MSNs. Moreover, comparing paired recording with current injection, our optogenetic stimulation protocol most likely activated a large number of D1 cells over a long period time. Therefore, ChIs may pool the effects of electrical transmission from multiple D1 neurons over a long period to exhibit a stronger excitatory response. Our use of multiple optogenetic tools allows us to observe clear electrical coupling between two neuron types, thus highlighting the advantage of cell type-specific optogenetics for studying electrical synapses.

Our observations provide a new mechanism to understand the tonically active firing patterns of ChIs. ChIs represent a key population of striatal interneurons and are involved in various aspects of signal processing in the striatum. Striatal ChIs in vivo show a spontaneous tonic firing activity and respond to the rewarding cues and associative motor learning-related stimuli with a transient pause followed by a rebound increase (Pisani et al., 2007). Striatal ChI firing drives spontaneous muscarinic activation in D1-MSNs (Mamaligas and Ford, 2016) and triggers GABA release from dopamine terminals to D1-MSNs (Nelson et al., 2014). Meanwhile, ChIs receive GABA transmission from D1-MSNs while responding to the dopamine inputs (Graybiel, 2000; Lahiri and Bevan, 2020). We find that in addition to the GABAergic, inhibitory transmission from D1-MSNs to ChIs, activating D1-MSNs promotes the basal activity of ChIs. Moreover, this outcome can be inhibited by gap junction blockers. Our results suggest that the gap junctions 
between D1-MSNs and ChIs may contribute to maintaining the tonically active firing patterns of ChIs, which have been implicated as key modulators of striatal microcircuits in the induction of synaptic plasticity, motor learning, and motor dysfunction (Abudukeyoumu et al., 2019).

This study also raises two questions that need to be further resolved. D1 MSNs have been reported to co-release GABA and SP onto ChIs (Bell et al., 1998; Govindaiah et al., 2010; Wang and Angulo, 2011; Francis et al., 2019). Consistently, we detected GABA release from D1-MSNs to ChIs via whole-cell recording. Francis et al. (2019) reported that high-frequency activation of D1-MSNs increased firing rates of ChIs and showed this can be inhibited by an SP blocker. In the present study, we applied whole-cell recordings to detect the currents induced by SP. Although SP blockers reduce slow inward currents in some ChIs induced by high-frequency activation of D1-MSNs, at the group level, they did not significantly suppress the inward currents, despite the presence of functional SP receptors on ChIs. SP release from D1 cells may also require certain modulation factors. For example, peptide neurokinin $B$ release from habenula neurons is induced only after presynaptic excitation via $\mathrm{GABA}_{\mathrm{B}}$ receptors (Zhang et al., 2016).

Moreover, the exact molecular identity of the gap junctions between D1 cells and ChIs remains to be dissected. In mammals, gap junction channels are encoded by a family of genes called "connexin $(C x)$," which can be categorized as dependent on the molecular mass of the connexin protein. Different connexin subunits can selectively interact with each other to form homotypic and heterotypic channels (Mese et al., 2007). In adult rats, MSNs express Cx31.1, Cx32, Cx36, and Cx47 (Venance et al., 2004). Single-cell sequence data in the striatum show that D1-MSNs mainly express Cx33 and $\mathrm{Cx} 45$ and striatal interneurons express Cx29, Cx33, Cx36, and Cx45 (Gokce et al., 2016; Munoz-Manchado et al., 2018). Cx36 has been reported to localize to the striatal interneurons, and deletion of Cx36 reduces the spontaneous activities of MSNs (Cummings et al., 2008). These studies support the possibility of gap junctions between D1-ChIs. However, our preliminary results indicate that knocking down several individual connexin-encoding genes fails to abolish the electrical coupling between D1 cells and ChIs (data not shown), suggesting the gap junction channels between D1 neurons and ChIs comprise two or more connexin proteins (Koval et al., 2014). Such heterotypic composition has been demonstrated in the inferior olive and in the deep cerebellar nuclei (Dere and Zlomuzica, 2012).

\section{REFERENCES}

Abudukeyoumu, N., Hernandez-Flores, T., Garcia-Munoz, M., and Arbuthnott, G. W. (2019). Cholinergic modulation of striatal microcircuits. Eur. J. Neurosci. 49, 604-622. doi: 10.1111/ejn.13949

Alvarez-Maubecin, V., Fernando, G. -H., Williams, J. T., and Bockstaele, A. E. J. V. (2000). Functional coupling between neurons and glia. J. Neurosci. 20, 40914098. doi: 10.1523/jneurosci.20-11-04091.2000

Andrade, E. L., Luiz, A. P., Ferreira, J., and Calixto, J. B. (2008). Pronociceptive response elicited by TRPA1 receptor activation in mice. Neuroscience 152, 511-520. doi: 10.1016/j.neuroscience.2007. 12.039
In summary, this study provides the first demonstration of electrical coupling between D1-type projection neurons and ChIs. Moreover, such coupling contributes to the tonic activation pattern of cholinergic neurons. Our study suggests that a precise understanding of striatal microcircuits needs to integrate information both from chemical synapses and electrical synapses in a cell type-specific manner. Finally, our experimental approach of integrating optogenetics with pharmacological interventions and electrophysiology should facilitate the process of studying the presence of both types of synaptic connections in the nervous system.

\section{DATA AVAILABILITY STATEMENT}

The original contributions presented in the study are included in the article/supplementary material, further inquiries can be directed to the corresponding author/s.

\section{ETHICS STATEMENT}

The animal study was reviewed and approved by the Animal Care and Use Committee of the National Institute of Biological Sciences, Beijing.

\section{AUTHOR CONTRIBUTIONS}

YR, YL, and ML designed the experiments. YR performed brain slice recordings, immunostaining, and surgeries. YL helped perform brain slice recordings. YR and ML analyzed the data and wrote the manuscript. All authors contributed to the article and approved the submitted version.

\section{FUNDING}

This study was supported by the Beijing Municipal Government.

\section{ACKNOWLEDGMENTS}

We thank YL (Peking University) for the Lari plasmid and JH Snyder, LH Lu and other Luo lab members for comments.

Aosaki, T., Kimura, M., and Graybiel, A. M. (1995). Temporal and spatial characteristics of tonically active neurons of the primate's striatum. J. Neurophysiol. 73, 1234-1252. doi: 10.1152/jn.1995.73.3. 1234

Assous, M., Kaminer, J., Shah, F., Garg, A., Koos, T., and Tepper, J. M. (2017). Differential processing of thalamic information via distinct striatal interneuron circuits. Nat. Commun. 8:15860. doi: 10.1038/ncomms 15860

Assous, M., and Tepper, J. M. (2019). Excitatory extrinsic afferents to striatal interneurons and interactions with striatal microcircuitry. Eur. J. Neurosci. 49, 593-603. doi: 10.1111/ejn.13881

Beck, P., Odle, A., Wallace-Huitt, T., Skinner, R. D., and Garcia-Rill, E. (2008). Modafinil increases arousal determined by P13 potential amplitude: an effect 
blocked by gap junction antagonists. Sleep 31, 1647-1654. doi: 10.1093/sleep/ 31.12.1647

Behrens, C. J., Ul Haq, R., Liotta, A., Anderson, M. L., and Heinemann, U. (2011). Nonspecific effects of the gap junction blocker mefloquine on fast hippocampal network oscillations in the adult rat in vitro. Neuroscience 192, 11-19. doi: 10.1016/j.neuroscience.2011.07.015

Bell, M. I., Richardson, P. J., and Lee, K. (1998). Characterization of the mechanism of action of tachykinins in rat striatal cholinergic interneurons. Neuroscience 87, 649-658. doi: 10.1016/s0306-4522(98)00187-0

Benedikt, J., Inyushin, M., Kucheryavykh, Y. V., Rivera, Y., Kucheryavykh, L. Y., Nichols, C. G., et al. (2012). Intracellular polyamines enhance astrocytic coupling. Neuroreport 23, 1021-1025. doi: 10.1097/WNR.0b013e3283 $5 \mathrm{aa} 04 \mathrm{~b}$

Blomeley, C., and Bracci, E. (2008). Substance P depolarizes striatal projection neurons and facilitates their glutamatergic inputs. J. Physiol. 586, 2143-2155. doi: 10.1113/jphysiol.2007.148965

Boyden, E. S., Zhang, F., Bamberg, E., Nagel, G., and Deisseroth, K. (2005). Millisecond-timescale, genetically targeted optical control of neural activity. Nat. Neurosci. 8, 1263-1268. doi: 10.1038/nn1525

Cachope, R., Mateo, Y., Mathur, B. N., Irving, J., Wang, H. L., Morales, M., et al. (2012). Selective activation of cholinergic interneurons enhances accumbal phasic dopamine release: setting the tone for reward processing. Cell. Rep. 2, 33-41. doi: 10.1016/j.celrep.2012.05.011

Calabresi, P., Centonze, D., Gubellini, P., Pisani, A., and Bernardi, G. (2000). Acetylcholine-mediated modulation of striatal function. Trends Neurosci. 23, 120-126. doi: 10.1016/s0166-2236(99)01501-5

Cummings, D. M., Yamazaki, I., Cepeda, C., Paul, D. L., and Levine, M. S. (2008). Neuronal coupling via connexin 36 contributes to spontaneous synaptic currents of striatal medium-sized spiny neurons. J. Neurosci. Res. 86, $2147-$ 2158. doi: 10.1002/jnr.21674

Dere, E., and Zlomuzica, A. (2012). The role of gap junctions in the brain in health and disease. Neurosci. Biobehav. Rev. 36, 206-217. doi: 10.1016/j.neubiorev. 2011.05.015

Emonds-Alt, X., Doutremepuich, J.-D., Heaulme, M., Neliat, G., Santucci, V., Steinberg, R., et al. (1993). In vitro and in vivo biological activities of SR140333, a novel potent non-peptide tachykinin NK1 receptor antagonist. Eur. J. Pharmacol. 250, 403-413. doi: 10.1016/0014-2999(93)90027-f

English, D. F., Ibanez-Sandoval, O., Stark, E., Tecuapetla, F., Buzsaki, G., Deisseroth, K., et al. (2011). GABAergic circuits mediate the reinforcementrelated signals of striatal cholinergic interneurons. Nat. Neurosci. 15, 123-130. doi: 10.1038/nn.2984

Ferreira, J., Triches, K. M., Medeiros, R., and Calixto, J. B. (2005). Mechanisms involved in the nociception produced by peripheral protein kinase $\mathrm{c}$ activation in mice. Pain 117, 171-181. doi: 10.1016/j.pain.2005.06.001

Francis, T. C., Yano, H., Demarest, T. G., Shen, H., and Bonci, A. (2019). HighFrequency Activation of Nucleus Accumbens D1-MSNs Drives Excitatory Potentiation on D2-MSNs. Neuron 103:432-444.e3. doi: 10.1016/j.neuron.2019. 05.031

Galarreta, M., and Hestrin, S. (2001). Electrical synapses between GABA-releasing interneurons. Nat. Rev. Neurosci. 2, 425-433. doi: 10.1038/35077566

Gerfen, C. R. (1992). The neostriatal mosaic: multiple levels of compartmental organization in the basal ganglia. Ann. Rev. Neurosci. 15, 285-320. doi: 10.1146/ annurev.ne.15.030192.001441

Gerfen, C. R. (2000). Molecular effects of dopamine on striatal-projection pathways. Trends Neurosci. 23, S64-70.

Gokce, O., Stanley, G. M., Treutlein, B., Neff, N. F., Camp, J. G., Malenka, R. C., et al. (2016). Cellular Taxonomy of the Mouse Striatum as Revealed by SingleCell RNA-Seq. Cell. Rep. 16, 1126-1137. doi: 10.1016/j.celrep.2016.06.059

Goldberg, J. A., and Reynolds, J. N. J. (2011). Spontaneous firing and evoked pauses in the tonically active cholinergic interneurons of the striatum. Neuroscience 198, 27-43. doi: 10.1016/j.neuroscience.2011.08.067

Govindaiah, G., Wang, Y., and Cox, C. L. (2010). Substance P selectively modulates GABA(A) receptor-mediated synaptic transmission in striatal cholinergic interneurons. Neuropharmacology 58, 413-422. doi: 10.1016/j.neuropharm. 2009.09.011

Graybiel, A. M. (2000). The basal ganglia. Curr. Biol. 10, R509-11.

Guo, Q., Wang, D., He, X., Feng, Q., Lin, R., Xu, F., et al. (2015). Wholebrain mapping of inputs to projection neurons and cholinergic interneurons in the dorsal striatum. PLoS One 10:e0123381. doi: 10.1371/journal.pone.01 23381

Han, X., Chow, B. Y., Zhou, H., Klapoetke, N. C., Chuong, A., Rajimehr, R., et al. (2011). A high-light sensitivity optical neural silencer: development and application to optogenetic control of non-human primate cortex. Front. Syst. Neurosci. 5:18. doi: 10.3389/fnsys.2011.00018

Higley, M. J., Gittis, A. H., Oldenburg, I. A., Balthasar, N., Seal, R. P., Edwards, R. H., et al. (2011). Cholinergic Interneurons Mediate Fast VGluT3-Dependent Glutamatergic Transmission in the Striatum. PLoS One 6:e19155. doi: 10.1371/ journal.pone.0019155

Hinckley, C. A., and Ziskind-Conhaim, L. (2006). Electrical Coupling between Locomotor-Related Excitatory Interneurons in the Mammalian Spinal Cord. J. Neurosci. 26, 8477-8483. doi: 10.1523/jneurosci.0395-06.2006

Hormuzdi, S. G., Filippov, M. A., Mitropoulou, G., Monyer, H., and Bruzzone, R. (2004). Electrical synapses: a dynamic signaling system that shapes the activity of neuronal networks. Biochim. Biophys. Acta 1662, 113-137. doi: 10.1016/j. bbamem.2003.10.023

Hu, F., Ren, J., Zhang, J. E., Zhong, W., and Luo, M. (2012). Natriuretic peptides block synaptic transmission by activating phosphodiesterase $2 \mathrm{~A}$ and reducing presynaptic PKA activity. Proc. Natl. Acad. Sci. U. S. A. 109, 17681-17686. doi: 10.1073/pnas. 1209185109

Huang, W. Q., Wang, J. G., Chen, L., Wei, H. J., and Chen, H. (2010). SR140333 counteracts NK-1 mediated cell proliferation in human breast cancer cell line T47D. J. Exp. Clin. Cancer Res. 29:55. doi: 10.1186/1756-996629-55

Ibanez-Sandoval, O., Tecuapetla, F., Unal, B., Shah, F., Koos, T., and Tepper, J. M. (2011). A novel functionally distinct subtype of striatal neuropeptide Y interneuron. J. Neurosci. 31, 16757-16769. doi: 10.1523/JNEUROSCI.2628-11. 2011

Ikeda, H., Heinke, B., Ruscheweyh, R., and Sandkühler, J. (2003). Synaptic plasticity in spinal lamina I projection neurons that mediate hyperalgesia. Science 299, 1237-1240. doi: 10.1126/science.1080659

Koós, T., and Tepper, A. J. M. (1999). Inhibitory control of neostriatal projection neurons by GABAergic interneurons. Nat. Neurosci. 2, 467-472. doi: 10.1038/ 8138

Koval, M., Molina, S. A., and Burt, J. M. (2014). Mix and match: investigating heteromeric and heterotypic gap junction channels in model systems and native tissues. FEBS Lett. 588, 1193-1204. doi: 10.1016/j.febslet.2014. 02.025

Kreitzer, A. C. (2009). Physiology and pharmacology of striatal neurons. Ann. Rev. Neurosci. 32, 127-147. doi: 10.1146/annurev.neuro.051508.135422

Kumar, N. M., and Gilula, N. B. (1996). The gap junction communication channel. Cell 84, 381-388. doi: 10.1016/s0092-8674(00)81282-9

Lahiri, A. K., and Bevan, M. D. (2020). Dopaminergic Transmission Rapidly and Persistently Enhances Excitability of D1 Receptor-Expressing Striatal Projection Neurons. Neuron 106:277-290.e6. doi: 10.1016/j.neuron.2020. 01.028

Lapato, A. S., and Tiwari-Woodruff, S. K. (2018). Connexins and pannexins: at the junction of neuro-glial homeostasis \& disease. J. Neurosci. Res. 96, 31-44. doi: $10.1002 /$ jnr. 24088

Lefler, Y., Yarom, Y., and Uusisaari, M. Y. (2014). Cerebellar inhibitory input to the inferior olive decreases electrical coupling and blocks subthreshold oscillations. Neuron 81, 1389-1400. doi: 10.1016/j.neuron.2014.02.032

Levine, M. S., Fisher, Y. E., and André, V. M. (2011). Altered Balance of Activity in the Striatal Direct and Indirect Pathways in Mouse Models of Huntington's Disease. Front. Syst. Neurosci. 5:46. doi: 10.3389/fnsys.2011.00046

Li, Y., Zeng, J., Zhang, J., Yue, C., Zhong, W., Liu, Z., et al. (2018). Hypothalamic Circuits for Predation and Evasion. Neuron 97, 911-924.e5. doi: 10.1016/j. neuron.2018.01.005

Lobo, M. K. (2009). Molecular Profiling of Striatonigral and Striatopallidal Medium Spiny Neurons past, present, and future. Int. Rev. Neurobiol. 89, 1-35. doi: 10.1016/s0074-7742(09)89001-6

Lobo, M. K., Karsten, S. L., Gray, M., Geschwind, D. H., and Yang, X. W. (2006). FACS-array profiling of striatal projection neuron subtypes in juvenile and adult mouse brains. Nat. Neurosci. 9, 443-452. doi: 10.1038/nn1654

Mamaligas, A. A., and Ford, C. P. (2016). Spontaneous Synaptic Activation of Muscarinic Receptors by Striatal Cholinergic Neuron Firing. Neuron 91, 574 586. doi: 10.1016/j.neuron.2016.06.021 
Manjarrez-Marmolejo, J., and Franco-Pérez, J. (2016). Gap junction blockers: an overview of their effects on induced seizures in animal models. Curr. Neuropharmacol. 14, 759-771. doi: 10.2174/1570159x14666160603115942

Mese, G., Richard, G., and White, T. W. (2007). Gap junctions: basic structure and function. J. Invest. Dermatol. 127, 2516-2524. doi: 10.1038/sj.jid.5700770

Meyer, A. H., Katona, I., Blatow, M., Rozov, A., and Monyer, H. (2002). In vivo labeling of parvalbumin-positive interneurons and analysis of electrical coupling in identified neurons. J. Neurosci. 22, 7055-7064. doi: 10.1523/ jneurosci.22-16-07055.2002

Morita, M., Saruta, C., Kozuka, N., Okubo, Y., Itakura, M., Takahashi, M., et al. (2007). Dual regulation of astrocyte gap junction hemichannels by growth factors and a pro-inflammatory cytokine via the mitogen-activated protein kinase cascade. Glia 55, 508-515. doi: 10.1002/glia.20471

Munoz-Manchado, A. B., Bengtsson Gonzales, C., Zeisel, A., Munguba, H., Bekkouche, B., Skene, N. G., et al. (2018). Diversity of Interneurons in the Dorsal Striatum Revealed by Single-Cell RNA Sequencing and PatchSeq. Cell. Rep. 24, 2179-2190.e7. doi: 10.1016/j.celrep.2018.07.053

Nagel, G., Szellas, T., Huhn, W., Kateriya, S., Adeishvili, N., Berthold, P., et al. (2003). Channelrhodopsin-2, a directly light-gated cation-selective membrane channel. Proc. Natl. Acad. Sci. U. S. A. 100, 13940-13945. doi: 10.1073/pnas. 1936192100

Nedergaard, M. (1994). Direct signaling from astrocytes to neurons in cultures of mammalian brain cells. Science 263, 1768-1771. doi: 10.1126/science.8134839

Nelson, A. B., Hammack, N., Yang, C. F., Shah, N. M., Seal, R. P., and Kreitzer, A. C. (2014). Striatal cholinergic interneurons Drive GABA release from dopamine terminals. Neuron 82, 63-70. doi: 10.1016/j.neuron.2014.01.023

Owen, S. F., Liu, M. H., and Kreitzer, A. C. (2019). Thermal constraints on in vivo optogenetic manipulations. Nat. Neurosci. 22, 1061-1065. doi: 10.1038/s41593019-0422-3

Pereda, A. E. (2014). Electrical synapses and their functional interactions with chemical synapses. Nat. Rev. Neurosci. 15, 250-263. doi: 10.1038/nrn3708

Pisani, A., Bernardi, G., Ding, J., and Surmeier, D. J. (2007). Re-emergence of striatal cholinergic interneurons in movement disorders. Trends Neurosci. 30, 545-553. doi: 10.1016/j.tins.2007.07.008

Ren, J., Qin, C., Hu, F., Tan, J., Qiu, L., Zhao, S., et al. (2011). Habenula "cholinergic" neurons co-release glutamate and acetylcholine and activate postsynaptic neurons via distinct transmission modes. Neuron 69, 445-452. doi: 10.1016/j. neuron.2010.12.038

Robinson, J. E., Fish, E. W., Krouse, M. C., Thorsell, A., Heilig, M., and Malanga, C. J. (2012). Potentiation of brain stimulation reward by morphine: effects of neurokinin-1 receptor antagonism. Psychopharmacology 220, 215-224. doi: 10.1007/s00213-011-2469-z

Ross, F., Gwyn, P., Spanswick, D., and Davies, S. J. N. (2000). Carbenoxolone depresses spontaneous epileptiform activity in the CA1 region of rat hippocampal slices. Neuroscience 100, 789-796. doi: 10.1016/s0306-4522(00) 00346-8

Simon, A., Olah, S., Molnar, G., Szabadics, J., and Tamas, G. (2005). Gap-junctional coupling between neurogliaform cells and various interneuron types in the neocortex. J. Neurosci. 25, 6278-6285. doi: 10.1523/JNEUROSCI.1431-05.2005

Sohl, G., Maxeiner, S., and Willecke, K. (2005). Expression and functions of neuronal gap junctions. Nat. Rev. Neurosci. 6, 191-200. doi: 10.1038/nrn1627

Sosulina, L., Strippel, C., Romo-Parra, H., Walter, A. L., Kanyshkova, T., Sartori, S. B., et al. (2015). Substance P excites GABAergic neurons in the mouse central amygdala through neurokinin 1 receptor activation. J. Neurophysiol. 114, 2500-2508. doi: 10.1152/jn.00883.2014

Spray, D. C., Iglesias, R., Shraer, N., Suadicani, S. O., Belzer, V., Hanstein, R., et al. (2019). Gap junction mediated signaling between satellite glia and neurons in trigeminal ganglia. Glia 67, 791-801. doi: 10.1002/glia.23554
Szydlowski, S. N., Pollak Dorocic, I., Planert, H., Carlen, M., Meletis, K., and Silberberg, G. (2013). Target selectivity of feedforward inhibition by striatal fastspiking interneurons. J. Neurosci. 33, 1678-1683. doi: 10.1523/JNEUROSCI. 3572-12.2013

Tepper, J. M., Koos, T., Ibanez-Sandoval, O., Tecuapetla, F., Faust, T. W., and Assous, M. (2018). Heterogeneity and Diversity of Striatal GABAergic Interneurons: update 2018. Front. Neuroanat. 12:91. doi: 10.3389/fnana.2018. 00091

Tepper, J. M., Tecuapetla, F., Koos, T., and Ibanez-Sandoval, O. (2010). Heterogeneity and diversity of striatal GABAergic interneurons. Front. Neuroanat. 4:150. doi: 10.3389/fnana.2010.00150

Tervo, D. G., Hwang, B. Y., Viswanathan, S., Gaj, T., Lavzin, M., Ritola, K. D., et al. (2016). A Designer AAV Variant Permits Efficient Retrograde Access to Projection Neurons. Neuron 92, 372-382. doi: 10.1016/j.neuron.2016. 09.021

Threlfell, S., Lalic, T., Platt, N. J., Jennings, K. A., Deisseroth, K., and Cragg, S. J. (2012). Striatal dopamine release is triggered by synchronized activity in cholinergic interneurons. Neuron 75, 58-64. doi: 10.1016/j.neuron.2012. 04.038

Tuluc, F., Lai, J. P., Kilpatrick, L. E., Evans, D. L., and Douglas, S. D. (2009). Neurokinin 1 receptor isoforms and the control of innate immunity. Trends Immunol. 30, 271-276. doi: 10.1016/j.it.2009.03.006

Urban-Ciecko, J., and Barth, A. L. (2016). Somatostatin-expressing neurons in cortical networks. Nat. Rev. Neurosci. 17, 401-409. doi: 10.1038/nrn.2016.53

Vandecasteele, M., Deniau, J. M., Glowinski, J., and Venance, L. (2007). Electrical synapses in basal ganglia. Rev. Neurosci. 18, 15-35. doi: 10.1515/revneuro.2007. 18.1.15

Venance, L., Glowinski, J., and Giaume, C. (2004). Electrical and chemical transmission between striatal GABAergic output neurones in rat brain slices. J. Physiol. 559, 215-230. doi: 10.1113/jphysiol.2004.065672

Venance, L., Rozov, A., Blatow, M., Burnashev, N., Feldmeyer, D., and Monyer, H. (2000). Connexin expression in electrically coupled postnatal rat brain neurons. Proc. Natl. Acad. Sci. U. S. A. 97, 10260-10265. doi: 10.1073/pnas.1600 37097

Wang, J., and Angulo, J. A. (2011). Methamphetamine induces striatal neurokinin1 receptor endocytosis primarily in somatostatin/NPY/NOS interneurons and the role of dopamine receptors in mice. Synapse 65, 300-308. doi: 10.1002/syn. 20848

Wang, K., Gong, J., Wang, Q., Li, H., Cheng, Q., Liu, Y., et al. (2014). Parallel pathways convey olfactory information with opposite polarities in Drosophila. Proc. Natl. Acad. Sci. U. S. A. 111, 3164-3169. doi: 10.1073/pnas.1317911111

Wu, L., Dong, A., Dong, L., Wang, S. Q., and Li, Y. (2019). PARIS, an optogenetic method for functionally mapping gap junctions. ELife 8:e43366. doi: 10.7554/ eLife.43366

Zhang, J., Tan, L., Ren, Y., Liang, J., Lin, R., Feng, Q., et al. (2016). Presynaptic Excitation via GABAB Receptors in Habenula Cholinergic Neurons Regulates Fear Memory Expression. Cell 166, 716-728. doi: 10.1016/j.cell.2016.06.026

Conflict of Interest: The authors declare that the research was conducted in the absence of any commercial or financial relationships that could be construed as a potential conflict of interest.

Copyright (C) 2021 Ren, Liu and Luo. This is an open-access article distributed under the terms of the Creative Commons Attribution License (CC BY). The use, distribution or reproduction in other forums is permitted, provided the original author(s) and the copyright owner(s) are credited and that the original publication in this journal is cited, in accordance with accepted academic practice. No use, distribution or reproduction is permitted which does not comply with these terms. 